\title{
Providers' Experiences Treating Chronic Pain Among Opioid-Dependent Drug Users
}

\author{
Karina M. Berg, MD, MS $S^{1,2}$, Julia H. Arnsten, $M D, M P H^{1,2,3}$, Galit Sacajiu, MD, MPH ${ }^{1,4}$, \\ and Alison Karasz, $\mathrm{PhD}^{4}$
}

'Department of Medicine, Albert Einstein College of Medicine and Montefiore Medical Center, Bronx, NY, USA; ${ }^{2}$ Department of Psychiatry \& Behavioral Sciences, Albert Einstein College of Medicine and Montefiore Medical Center, Bronx, NY, USA; ${ }^{3}$ Department of Epidemiology \& Population Health, Albert Einstein College of Medicine and Montefiore Medical Center, Bronx, NY, USA; ${ }^{4}$ Department of Family Medicine, Albert Einstein College of Medicine and Montefiore Medical Center, Bronx, NY, USA.

BACKGROUND: Successful management of chronic pain with opioid medications requires balancing opioid dependence and addiction with pain relief and restoration of function. Evaluating these risks and benefits is difficult among patients with chronic pain and preexisting addiction, and the ambiguity is increased for patients on methadone maintenance therapy for opioid dependence. Providers treating both chronic pain and addiction routinely make diagnostic and therapeutic decisions, but decision-making strategies in this context have not been well described.

OBJECTIVE: Our objective was twofold. We sought first to explore providers' perceptions of ambiguity, and then to examine their strategies for making diagnostic and treatment decisions to manage chronic pain among patients on methadone maintenance therapy.

DESIGN: Qualitative semi-structured interviews.

SETTING AND PARTICIPANTS: We interviewed healthcare providers delivering integrated medical care and substance abuse treatment to patients in a methadone maintenance program.

RESULTS: Providers treating pain and co-morbid addiction described ambiguity in all diagnostic and therapeutic decisions. To cope with this inherent ambiguity, most providers adopted one of two decision-making frameworks, which determined clinical behavior. One framework prioritized addiction treatment by emphasizing the destructive consequences of abusing illicit drugs or prescription medications; the other prioritized pain management by focusing on the destructive consequences of untreated pain. Identification with a decision-making framework shaped providers' experiences, including their treatment goals, perceptions of treatment risks, pain management strategies, and tolerance of ambiguity. Adherence to one of these two frameworks led to wide variation in pain management practices, which created tension among providers.

CONCLUSIONS: Providers delivering integrated medical care and substance abuse treatment to patients in a

Received March 20, 2008

Revised November 19, 2008

Accepted January 5, 2009

Published online February 3, 2009 methadone maintenance program found tremendous ambiguity in the management of chronic pain. Most providers adopted one of the two divergent heuristic frameworks we identified, which resulted in significant variations in pain management. To reduce variation and determine best practices, studies should examine clinically relevant endpoints, including pain, illicit drug use, prescription drug abuse, and functional status. Until then, providers managing chronic pain in patients with co-morbid addiction should attempt to reduce tension by acknowledging ambiguity and engaging in open discourse.

KEY WORDS: chronic pain; addiction; methadone; opioids; provider experiences; qualitative.

$\mathrm{J}$ Gen Intern Med 24(4):482-8

DOI: $10.1007 / \mathrm{s} 11606-009-0908-\mathrm{x}$

(c) Society of General Internal Medicine 2009

\section{INTRODUCTION}

Evidence-based medicine is intended to help physicians appraise scientific evidence and use it to guide clinical decisions. Yet uncertainty is present throughout the practice of medicine $\mathrm{e}^{1,2}$, and many decisions are made despite a paucity of empirical support ${ }^{3}$. Medical decision-making is complex and relies heavily on available evidence. Even when high quality evidence is available, practice variation may result from differences in clinical judgment or lack of adherence with clinical guidelines. However, practice variation is more likely when evidence is lacking, and decision-making strategies under these circumstances are less clear.

Over the past decade, despite substantial increases in the long-term use of opioids to treat pain ${ }^{4}$, evidence about the risks and benefits of chronic opioid pain management is just emerging, and many questions remain unanswered ${ }^{5}$. To successfully manage chronic pain with opioids, providers must balance analgesia and restoration of function with the risks of diversion, dependence, and addiction. Variability in opioid prescribing practices may be explained in part by the inherent uncertainty of the opioid risk-benefit equation ${ }^{6-10}$.

Long-term opioid replacement with methadone is a wellestablished treatment for opioid dependence. Though expert recommendations on the management of acute pain in patients on opioid replacement therapy have recently been 
published $^{19}$, chronic pain management in this population remains controversial $^{11-16}$, in part because current or former use of illicit drugs is strongly associated with prescription drug abuse $^{17,18}$. Though patients on opioid replacement therapy have a higher prevalence of chronic pain compared to the general population ${ }^{20,21}$, guidelines for the management of chronic pain in this population are lacking.

We interviewed providers delivering integrated medical care and substance abuse treatment to patients on methadone for opioid dependence. In general, the goal of opioid prescribing in substance abuse treatment settings is to restore function by minimizing drug use, while in primary care settings, the goal is to restore function by relieving pain. We chose this integrated setting because we anticipated that it might highlight the challenges inherent to managing pain in current and former opioid-dependent drug users.

Our objective was twofold. First, we sought to explore providers' perceptions of ambiguity, and then to examine their strategies for making diagnostic and treatment decisions to manage chronic pain among patients on methadone maintenance therapy. We used qualitative research methods, which are uniquely suited to the investigation of complex, contextualized, and poorly understood phenomena ${ }^{22}$.

\section{METHODS}

\section{Setting and Participants}

We conducted interviews at a substance abuse treatment program comprised of 12 methadone clinics located in the Bronx, New York. Each clinic houses one physician, and some include a physicians' assistant (PA), who delivers comprehensive primary care to a population of low-income primarily Hispanic and Black patients with current or former heroin use. We approached all 12 physicians and 4 PAs. No provider refused to participate. To maintain the confidentiality of this small sample of providers, we have limited descriptive characteristics and edited quotations to remove all potentially identifying details, such as sex or type of professional training. The study was approved by the Institutional Review Board of Montefiore Medical Center. All participants provided written informed consent.

\section{Data Collection}

From April 2003 to July 2003, we conducted semi-structured interviews by asking providers open-ended questions designed to elicit experiences managing chronic pain in their patients. One research assistant trained in qualitative interviewing conducted all the interviews. The interview guide was adapted to include optional probes and additional questions suggested during the early phases of analysis, and this iterative process continued throughout the study. All interviews were audiotaped and professionally transcribed.

\section{Data Analysis}

The analysis team consisted of three internists and one psychologist. Transcripts were independently read by two investigators (KB and $\mathrm{AK}$ ) who took notes and met to discuss emerging themes. After we discussed a small number of initial interviews, we collaboratively developed a preliminary coding scheme. The coding scheme evolved as we read additional interviews, refined existing topics, and identified new themes. We stopped sampling when no new concepts emerged with successive interviews. Once consensus on the final coding structure was reached, two authors (KB and $\mathrm{AK}$ ) independently coded the transcripts in N-Vivo (QSR International, Bakersfield, CA) and then compared codes to ensure conceptual reliability.

The analysis included three consecutive phases, and we present our results chronologically. During the preliminary reading of transcripts, an unexpected dichotomy in decisionmaking frameworks became apparent and served as the organizing principle for the subsequent phases. The second phase was descriptive and involved intensive reviewing of codes across interviews. In the final phase, we analyzed how the contents of the thematic coding fit into the organizational framework.

\section{RESULTS \\ Demographic Characteristics of the Sample}

Ten of the 17 providers were female with a mean age of 39 years. Providers identified themselves as White, AfricanAmerican, Asian, Hispanic (of White or Black race), and all were trained in primary care specialties. In addition, three providers were certified in addiction medicine, and none had sub-specialty training in pain management. The median time practicing in a substance abuse treatment setting was 5 years (interquartile range, 2-10 years).

\section{Tools for Pain Management}

General pain management strategies varied by provider. To monitor adherence to pain medications, providers used directly observed therapy, short prescribing intervals, frequent follow-up visits, and urine toxicology tests to check for the presence of prescribed opioids. Providers could refer to an offsite pain clinic or physical therapy, but on-site support for pain management was not available.

\section{Practicing in a Context of Ambiguity}

The ambiguity of pain. A central focus for many providers was the inherent ambiguity of pain treatment. Providers felt more comfortable treating chronic pain that was supported by concrete evidence. Arthritic pain, for example, was easier to treat because "you see it on film, bones rubbing on bones...you know they're suffering." In contrast, managing pain of unclear etiology was difficult.

I find it difficult because it's extremely subjective information, and if there's nothing documented, I find it hard to prescribe something. Being able to track something gives me more comfort than going by what you're telling me, or where it hurts, how often it hurts, and how deep it is, 'cause I like to see proof. (\#15)

This difficulty was even more pronounced when providers considered prescribing opioids.

You wanna be convinced that you're treating something and that what you're treating is real and warrants a narcotic medication. (\#2) 
We found striking differences among providers in the way they made diagnostic and treatment decisions. Individual providers could come to very different conclusions based on the same data.

When we're practicing alongside other people who have come to completely different conclusions, it really makes you think... have I been making the wrong decisions; did we get different information and come to different conclusions? Do we have different values that underlie our decision-making? (\#17)

Providers' individual decision-making strategies differed considerably from each other, causing anxiety for some providers.

So let's say I make a decision: I don't think this patient needs X, Y, Z analgesic. Then, depending on who I run into, I may get into all kinds of problems..."You're just being unfair because he's a drug addict and you should give him pain medication." But if I run into somebody else, they might say "No, that was fine, that was a good clinical decision." (\#7)

Decision-making frameworks. To cope with ambiguity, most providers adhered to a decision-making framework, which functioned as a heuristic. A heuristic is a guiding principle intended to simplify problem solving in poorly understood domains. Adhering to a decision-making framework helped providers cope with ambiguous diagnostic and therapeutic decisions across patients.

We identified two contrasting frameworks. One focused on the destructive consequences of drug abuse, whether by illicit drugs or prescription medication abuse, and the other emphasized the destructive consequences of untreated pain. Although two providers used elements of both frameworks, the majority adhered to one or the other, which led to wide variation in pain management practices. For convenience, we refer to them simply as "framework 1" and "framework 2."

In the following sections, we discuss how identification with a decision-making framework shaped providers' experiences, including their treatment goals, their perceptions and management of treatment risks, strategies for making decisions, and tolerance for ambiguity itself. Major characteristics of the two frameworks are listed in the Table 1.

\section{Treatment Goals}

Determining the goals of pain treatment in this setting was fraught with ambiguity. Providers in framework 1 found the very notion of prescribing opioids to drug users confusing. They had difficulty reconciling the prescription of opioids for pain with the mission of the clinic, which was to restore function by minimizing drug use.

We know there's a risk of medications being abused... and patients are already opiate dependent, so...how is this pill that I'm prescribing for you going to be different than using heroin? (\#10)

The concern is really a subtle issue...why is this patient still using opiates, if he's in treatment, and the treatment is for opiates? (\#9)
Table 1. Major Characteristics of Decision-Making Frameworks

\begin{tabular}{|c|c|c|}
\hline Characteristic & Framework 1 & Framework 2 \\
\hline $\begin{array}{l}\text { Likelihood of prescribing } \\
\text { opioids for chronic pain }\end{array}$ & Low & High \\
\hline $\begin{array}{l}\text { Perceived consequences } \\
\text { of chronic opioid pain } \\
\text { management }\end{array}$ & $\begin{array}{l}\text { Increased illicit } \\
\text { drug use }\end{array}$ & $\begin{array}{l}\text { Decreased illicit } \\
\text { drug use }\end{array}$ \\
\hline $\begin{array}{l}\text { Definition of } \\
\text { prescription drug } \\
\text { abuse }\end{array}$ & Broad & Narrow \\
\hline $\begin{array}{l}\text { Response to } \\
\text { possible diversion }\end{array}$ & $\begin{array}{l}\text { Terminate } \\
\text { relationship }\end{array}$ & $\begin{array}{l}\text { Maintain } \\
\text { relationship }\end{array}$ \\
\hline $\begin{array}{l}\text { Perceived likelihood } \\
\text { of disciplinary } \\
\text { consequences }\end{array}$ & High & Low \\
\hline $\begin{array}{l}\text { Likelihood of } \\
\text { treatment referral }\end{array}$ & High & Low \\
\hline $\begin{array}{l}\text { Strategy to determine } \\
\text { authenticity of pain }\end{array}$ & $\begin{array}{l}\text { Patient adherence } \\
\text { with follow-up and } \\
\text { referral appointments }\end{array}$ & $\begin{array}{l}\text { Patient response } \\
\text { to early trial } \\
\text { of opioids }\end{array}$ \\
\hline
\end{tabular}

In contrast, providers using framework 2 acknowledged the potential conflict between pain and addiction treatment, but considered pain relief the paramount goal.

You get to the point where you really have to do what's compassionate, what's best for the patient regardless of their drug history, so that's really the overriding issue... how to get a patient comfortable. (\#7)

I mean there are two mistakes you make. You can make the mistake of under treating or of giving medicines that end up being sold or used for unintended purposes. You're going to make errors both ways, and I think it's generally better to risk opiates being misused versus not treating someone's pain. (\#11)

\section{Perception and Management of Treatment Risks}

All providers were aware of risks associated with opioid treatment. Major risks of treatment included the potential for abuse, diversion, and deception, as well as providers' fear of disciplinary consequences.

Risk of abuse. Providers most often mentioned the risk of prescription drug abuse. However, the definition of abuse tended to align with providers' decision-making frameworks. Providers using framework 1 described a broad definition of "abuse."

Abusing means instead of popping one pill, they pop two, three, four or taking somebody else's medication...even for pain management, just self-medicating. (\#14)

This definition of abuse included any use that resulted in euphoria.

If somebody in pain is taking extra medication to feel the euphoria, that's not acceptable. (\#8) 
By contrast, the definition of abuse was narrower for providers using framework 2. For example, achieving euphoria did not constitute 'abuse' if pain treatment goals were being met.

If someone was using the appropriate pain medicine and an hour later they were getting euphoric from it, I would say to myself..."the real issue is, are they doing well functionally on that dose?" Pain relief is about more than analgesia; it's about restoration of function. (\#4)

Three providers were concerned that patients with inadequate analgesia would turn to illicit drugs.

Their frustration is nobody's listening and nobody's taking care of it, and heroin is a pretty good drug to treat pain...if they feel bad and they're not getting treated, they'll go out and take care of it. (\#13)

It's more likely that untreated chronic pain would lead to substance abuse than chronic pain treated properly. Some patients return to street drugs because they're not getting what they need. (\#1)

Risk of diversion. All providers were concerned about diversion, or patients selling their opioid medications. However, approaches to the risk of diversion varied considerably. When confronted with the mere possibility of diversion, providers adhering to framework 1 terminated the patient-provider relationship. By contrast, providers using framework 2 might confront the patient directly.

You need to let the patient know in a professional but firm manner that selling the medication was wrong, "that's dangerous behavior, you can get hurt, we don't want that for you, we want you to do better than that." (\#4)

Providers adhering to framework 2 might also consider possible diversion part of a larger, more complex problem.

When there's a patient who is having multiple substance abuse issues, we try to define one or two steps to try to help that patient...start the process of treating herself. Eventually you might get to the point where you can address the possible diversion of the medications. (\#5)

Diversion could be a rational choice if it derived from a patient's need to pay for food or housing. In these cases, diversion did not necessarily rule out chronic pain.

...it's also a decision on the person's part...maybe you'll sell your pain medicines to prevent eviction and go through the pain. (\#11)

Risk of deception. The risk of deception was a common theme, and providers had numerous troubling recollections of being deceived by patients.

They're telling you it really hurts, it really hurts, my leg really hurts, but they're not limping into your exam room, they're comfortable in the chair, and you've seen them jump all around in the waiting room talking to friends. (\#1)

Being deceived was troubling for providers.

I've had trust in people, and it's been betrayed-sometimes the trust is betrayed multiple times. I find I'm not always that great a judge of who to trust and who not to trust, so, I don't trust my own judgment on trust all the time. (\#11)

However, the degree to which providers perceived deception as a risk differed between the two groups. For example, providers using framework 1 tended to blame themselves for making decisions that were based on misinformation.

I think people feel like they've been violated, you know, cheated, like they've been taken advantage of. I feel some of that, too. Ultimately you feel you've made a poor judgment, and you get mad at yourself. (\#11)

They expressed frustration with the task of distinguishing lies from truth.

It just takes a lot of energy, and then you don't even know what you're treating cause they'll come in with some bogus story, and then when you examine them, none of their story fits with what they have, and you have to say, "what is the point, what do you want?" (\#12)

In contrast, providers using framework 2 viewed deception as less common.

I've had the more stereotyped issue where you feel like you're being worked over, you know the feeling of getting scammed, and I think that for me it's really happened in such a minority of my patients, and it's not been my dominant experience. (\#17)

These providers were more willing to treat patients with chronic pain, despite the possibility of being deceived, and accepted their fallibility in the case of a bad decision.

My impression was that he had a true ankle problem. Then you find out it was all lies, but you know, at that time and at that moment, that was my assessment, and I did it. You're allowed to make mistakes. (\#5)

Risk of disciplinary consequences. Providers frequently mentioned the risk of disciplinary consequences and were aware of potentially devastating regulatory or legal outcomes.

In practicing medicine, there's a certain part of my brain at some level subconsciously that's reading my notes from the theoretical perspective of an outside observer. If something bad happens to this patient, how is it going to look if someone reviews this chart? (\#10)

However, providers using framework 1 were generally more concerned about such consequences. Several expressed a fear 
of regulatory agencies that might "show up at any time" and "audit the charts randomly."

Knock on wood, but you know, god knows, maybe I'll get a call from the FDA: "you've been prescribing [opioids] to this patient... so tell me why you're doing this.” (\#8)

Providers using framework 2 , on the other hand, felt that regulatory consequences were unlikely with well-documented and reasonable clinical decisions.

\section{Pain Management Strategies}

Within each framework, providers used various strategies to help make diagnostic and therapeutic decisions. We found that pain management strategies differed across the two groups. For example, a common strategy for providers using framework 1 was to defer making decisions by referring patients for diagnostic testing or to a specialty clinic. The authenticity of the pain was then judged based on the patients' adherence with follow-up.

If somebody new walks in, you don't know the patient... the patient doesn't know you. So you really can't trust what the patient is going to do. That's why you try to have multiple encounters and follow-up visits, and send for diagnostic workup to see how the patient is really compliant with it. And, if the patient is not compliant with the effort to make the diagnosis, I may not treat the patient. (\#8)

These providers tended to delay treatment until the patient completed diagnostic testing.

I said to this guy, "look, if you want pain medication from us, then you have to provide us with the last documented opiate prescription that you got from your outside doctor, get an MRI, get physical therapy, and think about going for a surgical referral." And he actually was relatively compliant with most of those things with the exception of his last opiate prescription, and I still have yet to get that, and this has been going on for a couple of months now. (\#3)

In contrast, providers using framework 2 employed a different set of strategies. Some prescribed opioids before achieving certainty about the authenticity of pain to keep the patient engaged in care.

I'd rather have this patient in my service than going to another doctor. People end up giving [medications], because if not, you're gonna lose the patient. (\#5)

Instead of making outside referrals, these providers might observe a patient's response to opioids as a test of the "authenticity" of the patient's pain.

You just have to jump in and...see how the patient responds, and sometimes you can tell from the response... are they coming back every week for a new prescription while the urine toxicology tests are showing that they are not taking it...versus they come back at appropriate intervals and report that their pain is getting better and are appropriately urine toxicology positive. (\#1)

\section{Response to Ambiguity}

Dealing with ambiguity was a universal challenge. However, providers' responses to uncertainty differed based on their heuristic framework. While providers adhering to framework 2 perceived ambiguity as a complex but necessary part of clinical medicine, some providers using framework 1 found the lack of certainty extremely anxiety provoking.

I'm a scientist, at least I like to have objective things, numbers, data, pictures, lab results. I actually don't like the challenge of trying to read a person's mind...you know, I loath it, I hate it with a, a deep, deep passion. (\#16)

\section{DISCUSSION}

Faced with the ambiguity of managing chronic pain in patients with pre-existing addiction disorders, most providers adhered to a decision-making framework that influenced their treatment goals, perceptions of treatment risks, pain management strategies, and tolerance for ambiguity. The two frameworks we identified corresponded to widely divergent pain management practices, which led to tension between providers.

Practice variation has been documented in numerous fields ${ }^{23-26}$, including pain treatment ${ }^{7}$ and opioid replacement therapy ${ }^{27,28}$. Variation has been attributed to difficulty interpreting scientific evidence ${ }^{29,30}$ and incorporating it into clinical practice $^{31}$, but little is known about how different strategies for clinical decision-making lead to different practice patterns. In this study, we describe an extremely ambiguous clinical scenario and two divergent heuristics that providers used to make necessary decisions.

Currently, there are no published data to conclusively support or refute either of these decision-making frameworks. It may be that successful treatment for pain and addiction requires using aspects of both. Future empirical studies should evaluate different pain management strategies and examine outcomes of pain, illicit drug use, prescription drug abuse, and functional status among current and former drug users.

The wide practice variation among the providers we interviewed was partly explained by the perceived relationship between pain and illicit drug use. The few published studies on the association between inadequate analgesia and illicit drug use among patients on methadone maintenance therapy had inconsistent results, with some studies suggesting an association between pain and illicit drug use, particularly drugs with analgesic properties ${ }^{14,32}$, and others suggesting no association ${ }^{20}$. Though all providers in this study were clearly committed to delivering high quality care, opposing perceptions of the impact of pain on illicit drug use led to important differences in practice.

There are two potential avenues that may address the ambiguity faced by providers managing chronic pain in patients on methadone maintenance. The first requires establishing an evidence base for decision-making. Two central 
questions needing attention are: when does the provision of opioids for chronic pain management to patients with preexisting addiction increase the risk of illicit drug use and, conversely, when does withholding opioids increase self-medication of pain with illicit drugs? Currently, the subject of chronic pain management in patients with addiction, and particularly with opioid dependence, can best be described as pre-paradigmatic ${ }^{33}$. This concept, adopted from the philosophy of science, describes the "pre-history" phase of a discipline, during which there is wide disagreement about fundamental issues. While such a state persists, a field cannot be said to be truly scientific. Although opportunities for specialists in pain and addiction to share knowledge have recently been created $^{34}$, important clinical questions must be answered before these closely related scientific fields can be successfully integrated.

A second potential avenue to alleviate the dilemma of treating pain and co-morbid addiction requires minimizing tension between providers. Most providers we interviewed experienced difficulty coping with the ambiguity of making decisions about chronic opioid pain management. Our findings support those of Bendtsen et al., who reported that the quandary of prescribing opioids led to dissatisfaction with decisions, low self-esteem, and discontent with colleagues ${ }^{9}$. The tension for some providers derived from awareness of differences among colleagues, which is not unexpected since providers turn most often to colleagues for guidance in situations of clinical ambiguity ${ }^{35}$. Establishing an open forum for providers to discuss challenging scenarios might foster collaboration. Potential scenarios might include patients with documented pain syndromes and functional impairment who are actively using drugs or patients with high opioid tolerance who may need large doses of opioids for effective analgesia. Though instituting a general approach to assessing, treating, and monitoring pain might decrease tension, it may be necessary to simply acknowledge ambiguity and accept variation in practice.

Limitations to our study should be noted. Our study sample was neither random not representative, and the providers' overall knowledge about specific pain management issues, such as opioid-induced hyperalgesia, is unclear. Further, the setting was unique, and while it does not invalidate our findings, regional or local culture may have influenced provider's concerns. Lastly, without larger, more representative sampling, these results should not be generalized to primary care providers in other settings or to pain specialists.

In summary, in a convenience sample of providers delivering integrated primary medical care and substance abuse treatment to patients on methadone maintenance for opioid dependence, we found that clinical ambiguity was a major barrier to making diagnostic and therapeutic decisions about chronic opioid pain management. To enable consistency, most providers adhered to one of two decision-making frameworks. Differences between frameworks led to differences in strategies to assess and treat chronic pain, and the resultant wide practice variation led to tension between providers. To establish an evidence base, research addressing the clinical intersection between pain and addiction should focus on the relationship between chronic opioid pain treatment and illicit drug use. Such efforts have the potential to guide health-care providers faced with this complex high-risk scenario and to provide effective chronic pain treatment for opioid-dependent drug users.

Acknowledgements: Portions of this project were presented at the Society of General Internal Medicine 29th Annual Meeting in April 2006. This study was funded by a grant from the National Institutes of Health to Dr. Arnsten (R25 DA14551). The authors thank the providers for their participation and Leah Zallman for conducting the interviews. The authors report no conflicts of interest.

Corresponding Author: Karina M. Berg, MD, MS; Division of General Internal Medicine, Montefiore Medical Center, 111 East 210th Street, Bronx, NY 10467, USA (e-mail: kberg@montefiore.org).

\section{REFERENCES}

1. Gerrity MS, Devellis RF, Earp JA. Physicians' reactions to uncertainty in patient care. A new measure and new insights. Med Care. 1990;28 (8):724-36.

2. Rizzo JA. Physician uncertainty and the art of persuasion. Soc Sci Med. 1993;37(12):1451-9.

3. Naylor CD. Grey zones of clinical practice: some limits to evidence-based medicine. Lancet. 1995;345(8953):840-2.

4. Zerzan JT, Morden NE, Soumerai S, et al. Trends and geographic variation of opiate medication use in state Medicaid fee-for-service programs, 1996 to 2002. Med Care. 2006;44(11):1005-10.

5. Eriksen J, Sjogren P, Bruera E, Ekholm O, Rasmussen NK. Critical issues on opioids in chronic non-cancer pain: an epidemiological study. Pain. 2006;125(1-2):172-9.

6. Turk DC, Brody MC, Okifuji EA. Physicians' attitudes and practices regarding the long-term prescribing of opioids for non-cancer pain. Pain. 1994;59(2):201-8.

7. Tamayo-Sarver JH, Dawson NV, Cydulka RK, Wigton RS, Baker DW. Variability in emergency physician decision making about prescribing opioid analgesics. Ann Emerg Med. 2004;43(4):483-93.

8. Potter M, Schafer S, Gonzalez-Mendez E, et al. Opioids for chronic nonmalignant pain. Attitudes and practices of primary care physicians in the UCSF/Stanford Collaborative Research Network. University of California, San Francisco. J Fam Pract. 2001;50(2):145-51.

9. Bendtsen $\mathbf{P}$, Hensing $\mathbf{G}$, Ebeling $\mathbf{C}$, Schedin $\mathbf{A}$. What are the qualities of dilemmas experienced when prescribing opioids in general practice? Pain. 1999;82(1):89-96.

10. Passik SD, Kirsh KL, Whitcomb L, Dickerson PK, Theobald DE. Pain clinicians' rankings of aberrant drug-taking behaviors. J Pain Palliat Care Pharmacother. 2002;16(4):39-49.

11. Collins ED, Streltzer J. Should opioid analgesics be used in the management of chronic pain in opiate addicts? Am J Addict. 2003;12 (2):93-100.

12. Hicks RD. Pain management in the chemically dependent patient. Hawaii Med J. 1989;48(11):491-5.

13. Merrill JO, Rhodes LA, Deyo RA, Marlatt GA, Bradley KA. Mutual mistrust in the medical care of drug users: the keys to the "narc" cabinet. J Gen Intern Med. 2002;17(5):327-33.

14. Trafton JA, Oliva EM, Horst DA, Minkel JD, Humphreys K. Treatment needs associated with pain in substance use disorder patients: implications for concurrent treatment. Drug Alcohol Depend. 2004;73(1):23-31.

15. Gilson AM, Joranson DE. U.S. policies relevant to the prescribing of opioid analgesics for the treatment of pain in patients with addictive disease. Clin J Pain. 2002;18(4 Suppl):S91-8.

16. Cohen MJ, Jasser S, Herron PD, Margolis CG. Ethical perspectives: opioid treatment of chronic pain in the context of addiction. Clin J Pain. 2002;18(4 Suppl):S99-107.

17. Michna E, Ross EL, Hynes WL, et al. Predicting aberrant drug behavior in patients treated for chronic pain: importance of abuse history. $J$ Pain Symptom Manage. 2004;28(3):250-8.

18. Ives TJ, Chelminski PR, Hammett-Stabler CA, et al. Predictors of opioid misuse in patients with chronic pain: a prospective cohort study. BMC Health Serv Res. 2006;6:46.

19. Alford DP, Compton P, Samet JH. Acute pain management for patients receiving maintenance methadone or buprenorphine therapy. Ann Intern Med. 2006;144(2):127-34. 
20. Rosenblum A, Joseph H, Fong C, Kipnis S, Cleland C, Portenoy RK. Prevalence and characteristics of chronic pain among chemically dependent patients in methadone maintenance and residential treatment facilities. JAMA. 2003;289(18):2370-78.

21. Jamison RN, Kauffman J, Katz NP. Characteristics of methadone maintenance patients with chronic pain. J Pain Symptom Manage. 2000;19(1):53-62.

22. Crabtree BF, Miller WL. Doing Qualitative Research. California: SAGE Publications; 1999.

23. Landon BE, Reschovsky J, Reed M, Blumenthal D. Personal, organizational, and market level influences on physicians' practice patterns: results of a national survey of primary care physicians. Med Care. 2001;39(8):889-905.

24. Vickrey BG, Gifford DR, Belin TR, et al. Practice styles of US compared to UK neurologists. Neurology. 1998;50(6):1661-8.

25. Fuat A, Hungin AP, Murphy JJ. Barriers to accurate diagnosis and effective management of heart failure in primary care: qualitative study. BMJ. 2003;326(7382):196.

26. Coulter A, Klassen A, MacKenzie IZ, McPherson K. Diagnostic dilatation and curettage: is it used appropriately? BMJ. 1993;306(6872):236-9.

27. D'Aunno T, Vaughn TE. Variations in methadone treatment practices. Results from a national study. JAMA. 1992;267(2):253-8.
28. Willenbring ML, Hagedorn HJ, Postier AC, Kenny M. Variations in evidence-based clinical practices in nine United States Veterans Administration opioid agonist therapy clinics. Drug Alcohol Depend. 2004;75 (1):97-106.

29. Cranney M, Walley T. Same information, different decisions: the influence of evidence on the management of hypertension in the elderly. Br J Gen Pract. 1996;46(412):661-3.

30. Ghosh AK, Ghosh K. Translating evidence-based information into effective risk communication: current challenges and opportunities. J Lab Clin Med. 2005;145(4):171-80.

31. Freeman AC, Sweeney $\mathbf{K}$. Why general practitioners do not implement evidence: qualitative study. BMJ. 2001;323(7321):1100-02.

32. Karasz A, Zallman L, Berg K, Gourevitch M, Selwyn P, Arnsten JH The experience of chronic severe pain in patients undergoing methadone maintenance treatment. J Pain Symptom Manage. 2004;28 (5):517-25.

33. Kuhn TS. The Structure of Scientific Revolutions. 3Chicago and London: The University of Chicago Press; 2008.

34. International Association of Pain and Chemical Dependency. Available at: http://www.iapcd.org/. Accessed November 11, 2008.

35. Tomlin Z, Humphrey C, Rogers S. General practitioners' perceptions of effective health care. BMJ. 1999;318(7197):1532-5. 